\title{
Simulation and Modeling of Reservoir Operation
}

\author{
Dr. VidyaShankar M.H \\ Assistant Professor, Dept. of Computer Science \\ Sahyadri Science College, Shivamogga.577203
}

\begin{abstract}
Reservoir operation is very important part of planning and management of water resource system. Water in the reservoir can be used for Agricultural purpose as well as Electricity generation. An attempt has been made in this paper by using a linear programming for optimal reservoir operation of Reservoirs. Asia's first hydro electric power station established in 1902 at Shivanasamudram. Karnataka was the first state to have longest transmission line in world in 1902 from shivanasamudram to Kolar gold Field covering distance of $147 \mathrm{KM}$. A case study of Mahadhayi River Project in Karnataka. In this study object function is to maximize the net benefits from Power generation in the system and release pattern to be adopted to maximize energy generation subjected to various constraints.
\end{abstract}

Key words: Reservoir,Rule curve, linear model

\section{INTRODUCTION}

Water energy is very necessary for humankind and it is the most important resource of the entire society. No life is possible without water; it has this unique position among other natural service.

Water can be put to various uses due to its unique properties. The water helps us for running our hydro electric turbines, the density of water helps us in floating our ships, the energy of water provide steam for running our locomotives and turbines, and also to warm our dwelling units; the electrical conductivity of water helps us in providing a wonderful solvent.

\section{RESERVOIR OPERATION}

A reservoir operation plan is devised to achieve the greatest value or benefit from the storage capacity. The plan must be based on a knowledge of the flow characteristics of the stream, i.e. a history of its past performance; the purposes of the reservoir must be analyzed to determine as to how the hydrograph of flow should be altered to produce the greatest benefits; and special considerations, such as the effect of sudden releases on stream banks and of long - sustained flows from the reservoir on agricultural developments in the alley below the reservoir.

Multipurpose storage reservoirs economically attractive than the single purpose reservoir. The manner in which the co-ordination of different purposes is realized is controlled by the most important utilization of the dam. This in turn is determined by the character of the areas. For instance, power generation is usually considered a secondary benefit in comparison to other uses, but in some instances power is the main objective. In such cases the full flood control capacity is provided as the surcharge capacity so that any restriction of power generation should be precluded.

Scope of the present paper

The objective of the present report is to describe the various methods used to derive the reservoir operating rules. With the advent of computers and developments in operation research theory. The application of system engineering techniques in reservoir operation is growing day-by-day. The techniques of simulation and optimization for reservoir operation can also be done as future plan.

\section{SYSTEM ENGINEERING OF RESERVOIR OPERATION:}

One of the most important advances made in the field of water resources engineering is the development and adaptation of system analysis techniques for planning, design and management of complex water resources system. The application of system approach to reservoir problems concerned with hydropower can be classified in to two categories; Optimization and Simulation based on the system technique to solve the problem.

Current study: 
The present work concentrated upon the optimal multi reservoir operation for the two reservoirs namely, Kotni dam and Irti dam of Mahadayi hydroelectric project. The next step involves the formulation of mathematical model for the reservoir operation.

The working table for reservoir operation has been prepared for the present study of Mahadayi hydroelectric project. The period considered for the present work is from 1975 AD to $2000 \mathrm{AD}$ (for both Kotni dam and Irti dam).

The monthly inflow details are collected from Karnataka Power Corporation Limited (KPCL), Bangalore. (Monsoon Months namely, June, July, August, September, October and Non monsoon months from November to May)

\section{ANALYSIS AND RESULTS:}

For this present study, the reservoir operation table or working table ( for both Kotni and Irti dam ) with diversion without diversion and the mathematical modeling is prepared.

The hydrological aspects of reservoir planning are :

1. Water availability in the river on which the dam is proposed to be constructed.

2. Determination of storage capacity to serve the target pattern of demand and

3. Operation of reservoir with the given target pattern of demand.

\section{STANDARD LINEAR OPERATING POLICY}

The simplest of the reservoir operation policies is the standard linear operating policy (SLOP). according to this policy, if the amount of water available in storage is less than the target release, whatever quantity is available is released, if availability is more than target then a release equal to the target is made as long as storage space is available to store excess water and thereafter, all the water in excess of maximum storage capacity is released. This policy is mathematically expressed as follows.

$\mathrm{Ri}=\mathrm{Si}+\mathrm{Ii}$ if $\mathrm{Si}+\mathrm{Ii}<=\mathrm{T}$

$\mathrm{T}$ if $\mathrm{T}<=\mathrm{Si}+\mathrm{Ii}<=\mathrm{T}+\mathrm{S} \max$

$\mathrm{Si}+\mathrm{Ii}-\mathrm{Smax}$ if $\mathrm{Si}+\mathrm{Ii}>=\mathrm{T}+\mathrm{Smax}$

where $\mathrm{Ri}=$ Release during time period $\mathrm{i}$,

$\mathrm{Si}=$ Storage at the beginning period $\mathrm{i}$,

$\mathrm{Ii}=$ Inflow during period $\mathrm{i}$,

$\mathrm{T}=$ Target for release

Smax = Maximum reservoir storage capacity.

In present study, the objective function is to maximize the net benefits from power generation in the system and the release pattern to be adopted to maximize energy generation subjected to various constraints. To utilize water for Domestic Purpose this includes Agriculture.

OBJECTIVE FUNCTION: subject to following constraints:

Continuity constraint: The water released during any period " $\mathrm{t}$ " cannot exceed the content of the reservoir at the beginning plus the inflow into the reservoir during period t.

For Kotni reservoir:

$\mathrm{KSt}+1=\mathrm{KSt}+\mathrm{KIT}-\mathrm{K} \mathrm{Su} \mathrm{t}-\mathrm{Q} \mathrm{Kt}-\mathrm{Div} \mathrm{t}$

$\mathrm{KSt}+\mathrm{K} \mathrm{Su} \mathrm{t}+\mathrm{QKt}=\mathrm{Kit}-\mathrm{K} \mathrm{Et}-\mathrm{Div} \mathrm{t}$

For Irti reservoir:

$\mathrm{ISt}+1=\mathrm{Ist}+\mathrm{Iit}-\mathrm{I} \mathrm{Su} \mathrm{t}-\mathrm{I} \mathrm{Et}-\mathrm{Q} \mathrm{It}+\mathrm{Q} \mathrm{Kt}$

Ist + I Sut + Qit - Q Kt $=$ I It - I Et

INEQUALITY CONSTRAINTS:

Releases $<=$ Availability

For kotni reservoir: $\quad$ Q Kt $+\mathrm{KSt}+\mathrm{K}$ Sut $<=\mathrm{Kit}-\mathrm{Ket}-\mathrm{Div} \mathrm{t}$

For Irti reservoir: $\quad$ Qit + ISt $+1+$ ISt + Isut $<=$ I It - I Et 
Capacity constraints:

Storage should be less than or equal to maximum capacity of the reservoir.

Maximum storage at the beginning of the period " $t$ " should be less than or equal to the capacity at FRL.

For Kotni reservoir:

$\mathrm{K} \mathrm{St}<=420.52 \quad$ (capacity at FRL in M.Cum)

For Irti reservoir:

I St $<=107.31$ (capacity at FRL in M.Cum)

Minimum storage at the beginning of the period $t$ should be greater than or equal to the capacity at the minimum draw down level (MDDL) in reservoir.

Minimum storage constraints:

For Kotni reservoir:

$\mathrm{K} \mathrm{St}<=49.17$ (storage capacity at MDDL in M.Cum)

For Irti reservoir:

I $\mathrm{St}<=72.36$ (storage capacity at MDDL in M.Cum)

Power constraints:

The withdrawal of power should not exceed the power draft for full installed capacity at Kotni power house and Irti power house are $20 \mathrm{MW}$ and $300 \mathrm{MW}$ respectively.

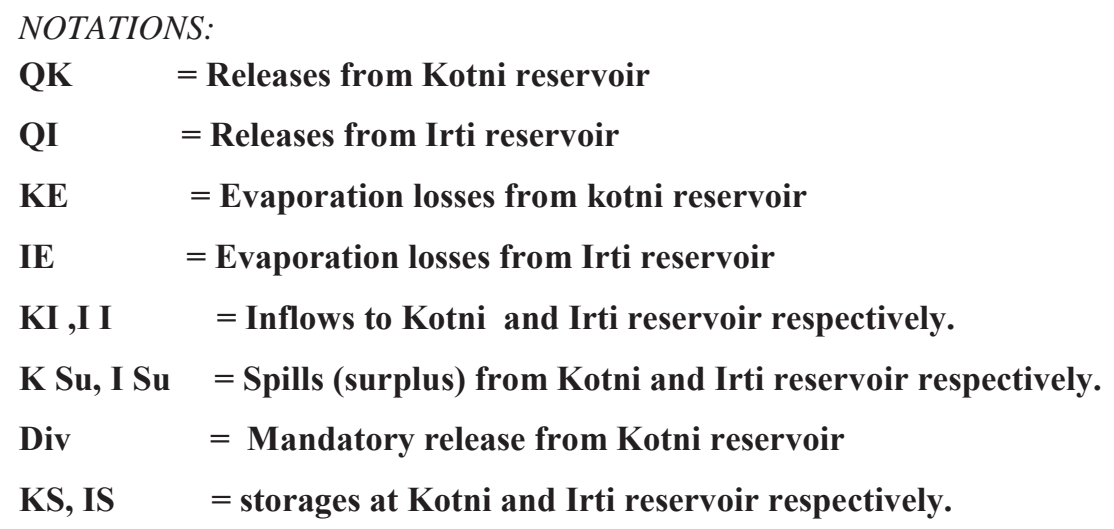

Planning models and solution procedures: Typical planning models generally include at least one objective function that is either maximized or minimized. Sometimes planning problem is stated in the form of maximizing an objective function subject to probabilistic constraints. One statement representing this class of constraint is the probability that the power produced is greater than or equal to the power requirement must not be less than .95 . Such a probabilistic constraint might be written as

$\operatorname{Pr}[$ power produced $>=$ power requirement ].$=0.95$ where 0.95 is the limit on the function fraction of time which the power requirement is to be met.

\section{CONCLUSION}

The operation of reservoirs is one of the most important aspects of water resources management. The complexity of the problem arises because of future uncertainty and the conflicting nature of demands placed on the reservoir. The types of conflicts, which may arise in the operation of a reservoir, have been discussed along with the functional requirements for various uses of water. Linear modeling is done for maximization of power with the different constraints of water release from supporting dams, and release pattern in mentioned.

Future plan is to adopt the system engineering techniques which is becoming more and more popular day-by-day, particularly with wider availability of computer simulation techniques.

\section{REFERENCES}

[1] Mahadayi hydro electric project by KPCL

[2] Hydrology by Ragunath

[3] Concepts of Hydrology by Mutreja 